\title{
EFEITO DE DIFERENTES CONDIÇÕES DE LUMINOSIDADE E SUBSTRATOS NO DESENVOLVIMENTO INICIAL DE GRAMA BERMUDA
}

\author{
João André do Amaral $^{1}$, Regina Maria Monteiro de Castilho ${ }^{2}$, Kuniko Iwamoto Haga ${ }^{3}$ \\ 1 Mestrando em Agronomia, Faculdade Engenharia - UNESP Câmpus de Ilha Solteira (SP). Email: \\ champignom2000@gmail.com \\ ${ }^{2}$ Docente do Departamento de Fitotecnia, Tecnologia de Alimentos e Sócio Economia, Faculdade Engenharia \\ - UNESP Câmpus de Ilha Solteira (SP). \\ ${ }^{3}$ Docente do Departamento de Biologia e Zootecnia, Faculdade Engenharia - UNESP Câmpus de Ilha Solteira \\ (SP).
}

RESUMO: A luminosidade e o tipo de substrato utilizado na implantação de gramados são alguns dos fatores que devem ser considerados na escolha da espécie de grama. Com a realização de eventos esportivos internacionais nos últimos anos no país, houve a necessidade de alterações arquitetônicas nas arenas, com a implantação de coberturas, aumentando o sombreamento do gramado e, deste modo, o presente estudo teve por objetivo avaliar a influência da luminosidade e de diferentes substratos no desenvolvimento inicial de grama bermuda (Cynodon dactylon $\mathrm{x} C$. transvaalensis). $\mathrm{O}$ experimento foi conduzido no Campus II - UNESP, de Ilha Solteira - SP, em esquema fatorial 5 x 4 (substratos x luminosidades), em delineamento inteiramente casualizado com 20 tratamentos e 3 repetições. Os substratos foram: $\mathrm{S} 1=\mathrm{Solo}, \mathrm{S} 2=\mathrm{Solo}+$ areia $(2: 1), \mathrm{S} 3=$ Solo + matéria orgânica (1:1), S4 = Solo + matéria orgânica + areia (2:1:1) e S5 = Matéria orgânica + areia (3:1), em 4 condições de luminosidade (pleno sol, 30\%, 50\%, 80\% de sombreamento), durante os meses de março de 2014 a agosto de 2014. Foram avaliados: Comprimento médio da parte aérea do gramado e massa fresca e massa seca das folhas. Foi possível concluir que níveis mais intensos de sombreamento estimularam o crescimento em comprimento da parte aérea da grama, porém houve uma redução no acúmulo de massa fresca e seca.

Palavras-chave: Cynodon dactylon $\mathrm{x} \quad$ C. transvaalensis. Gramados esportivos. Sombreamento. Topsoil.

\section{BERMUDAGRASS DEVELOPMENT UNDER DIFFERENT LIGHT CONDITIONS AND SUBSTRATES}

\begin{abstract}
The light conditions and the type of substrate used in lawn implantation are some of the factors that must be considerate when choosing a grass species. Due to the realization of international sportive events on the last few years in Brazil, there was a necessity of architectural changes in the arenas, the construction of roof, increasing the shade over the lawn, this way, the aim of present study is evaluate the light and different substrates influence in the initial development of Bermudagrass (Cynodon dactylon x $C$. transvaalensis). The experiment was conducted on Campus II - UNESP, in Ilha Solteira $\mathrm{SP}$, the experimental design used was completely randomized, in a factorial scheme $5 \times 4$
\end{abstract}

Cultura Agronômica, Ilha Solteira, v.25, n.3, p.291-302, 2016 
(substrates $x$ light conditions), studying 20 treatments and 3 repetitions. The substrates used were: $\mathrm{S} 1$ = soil, $\mathrm{S} 2=$ soil + sand $(2: 1), \mathrm{S} 3=$ soil + organic matter $(1: 1), \mathrm{S} 4=$ soil + organic matter + sand (2:1:1) and S5 = organic matter + sand (3:1), in 4 different light conditions (full sun, 30\%, 50\%, 80\% of shade), from march 2014 to august 2014. The evaluations: average lawn shoot length and fresh and dry mass of the leaves. More intense shade levels resulted in a bigger shoot length grow, however a lower fresh and dry mass accumulation was found.

Key words: Cynodon dactylon $x$ C. transvaalensis. Lawn. Shading. Topsoil.

\section{INTRODUÇÃO}

Os gramados trazem diversos benefícios para o meio ambiente, como por exemplo, o aumento da área permeável nas zonas urbanas, a liberação de $\mathrm{O}_{2}$, a redução na temperatura, etc, e também proporciona um local confortável e seguro para diversão e prática de esportes (GODOY, 2005; GODOY; VILLAS BÔAS, 2003).

Muitas são as gramas comercializadas com finalidades distintas, sendo as gramas bermuda (Cynodon spp.) as mais indicadas para formação de gramados esportivos, sendo muito utilizada em campos para prática de futebol, pólo, golfe, tênis, beisebol, etc. (OLIVEIRA et al., 2008).

Seguindo a recomendação do Comitê Organizador Brasileiro - Copa 2014 (2009), foram implantadas nas arenas de futebol gramas bermuda, principalmente híbridos destas, como é o caso dos cultivares Celebration e Tifton 419 (Tifway), por terem maior resistência ao pisoteio e regeneração mais rápida, além de maior maciez facilitando o rolamento da bola e amortecendo o impacto no pisar dos jogadores.

Pertencente ao grupo C4, as gramíneas necessitam de um suprimento a mais de energia, exigindo uma intensidade luminosa maior, devido a sua característica de reduzir as perdas de $\mathrm{CO}_{2}$, as plantas $\mathrm{C} 4$ são mais produtivas do que as plantas $\mathrm{C} 3$, porém sua eficiência na conversão de energia luminosa em energia química é menor (WHATLEY; WHATLEY, 1982).

O tipo de solo ou substrato também afeta o desenvolvimento do gramado. A composição do substrato afeta diretamente a textura do mesmo, também influenciando a sua predisposição a compactação, sendo as misturas ricas em argila mais propensas a compactação em relação aos substratos mais arenosos. Além disso, o tipo de mineral de argila também exerce influência, devido as diferenças nos arranjos das partículas em agregados e espaços porosos entre eles (MORAES et al., 2008).

Embora exista um crescente interesse nas gramas bermuda, tanto para projetos paisagísticos quanto esportivos, ainda há falta de informações na literatura em relação as condições mais favoráveis ao seu pleno desenvolvimento, deste modo, o presente trabalho tem como objetivo avaliar a influência de diferentes níveis de luminosidade e de diferentes 
substratos no desenvolvimento da grama bermuda (Cynodon dactylon x C. transvaalensis).

\section{MATERIAL E MÉTODOS}

O experimento foi conduzido no Campus II da Faculdade de Engenharia - UNESP, Campus de Ilha Solteira, com latitude $20^{\circ} 25^{\prime} \mathrm{S}$, longitude $51^{\circ} 21^{\prime}$ WGR e altitude de 330 m, no município de Ilha Solteira - SP, no período entre 22 de março e 22 de agosto de 2014. As médias das temperaturas máxima e mínima, registradas durante o período foram de $29,9^{\circ} \mathrm{C}$ e $17,0^{\circ} \mathrm{C}$, respectivamente; e as médias da umidade relativa máxima e mínima foram de $92,9 \%$ e $45,3 \%$, respectivamente. (UNESP, 2014).

O cultivar estudado foi o Tifway, também conhecido como Tifton 419 (híbrido interespecífico de Cynodon dactlylon x $C$. transvaalensis) e os tratamentos utilizados no experimento foram compostos de 5 tipos de substrato $[\mathrm{S} 1=$ Solo, $\mathrm{S} 2=$ Solo + areia $(2: 1)$, S3 = Solo + matéria orgânica (1:1), S4 = Solo + matéria orgânica + areia (2:1:1) e S5 = Matéria orgânica + areia (3:1)] e 4 níveis de luminosidade (pleno sol, 30\%, 50\% e 80\% de sombreamento), com 3 repetições cada tratamento.

A grama foi plantada em contêineres de plástico preto $(47,5 \mathrm{X} 17,5 \mathrm{~cm}$ boca, 41,5 X $11,3 \mathrm{~cm}$ fundo, altura $15,5 \mathrm{~cm}$, volume 8,46 litros), com a utilização de tapetes de dimensões 0,62 X 0,45 m, que foram recortados nas dimensões dos conteineres.

O solo utilizado na composição dos substratos foi classificado como Latossolo Vermelho distrófico textura franco-argilo-arenosa, segundo o Sistema Brasileiro de Classificação do Solo (EMBRAPA, 1999). A matéria-orgânica foi obtida através de processo de compostagem de resíduos vegetais, produzida na Fazenda de Ensino, Pesquisa e Extensão da UNESP, campus de Ilha Solteira, e a areia utilizada, foi adquirida em loja de materiais para construção, sendo denominada como areia grossa com granulometria entre 0,6 e $2,0 \mathrm{~mm}$.

Os níveis de sombreamento $(30,50$ e $80 \%)$ foram gerados com a utilização de telas de sombreamento de coloração preta, instaladas em uma estrutura de $1 \mathrm{~m}^{2}$ de vergalhão de ferro de $1 / 4$ de polegada.

O manejo da irrigação foi realizado diariamente de forma manual, sendo que os contêineres receberam água até a saturação, a fim de garantir que fosse atingida a Capacidade de Campo de cada substrato para que o fator água não interferisse nos resultados do experimento.

Foram realizadas análises de altura e massa fresca e seca da parte aérea de cada um dos tratamentos e suas repetições, sendo o comprimento da parte aérea da grama foi obtido anteriormente aos cortes, com a utilização de uma régua milimetrada, coletando-se os dados em três pontos em cada um dos tratamentos, calculando-se a média. Para a determinação da massa fresca e massa seca das folhas foram realizados cortes em cada um dos contêineres, mantendo a grama com $3 \mathrm{~cm}$ de altura, coletando-se as aparas e pesando-as em balança de precisão, sendo que a massa seca foi determinada após alocação das amostras em estufa de

Cultura Agronômica, Ilha Solteira, v.25, n.3, p.291-302, 2016 
ventilação forçada, a $60^{\circ} \mathrm{C}$, até que se verificasse massa constante.

O primeiro corte foi realizado aos 30 dias da implantação do experimento, e o segundo aos 150 dias. As coletas de dados de altura coincidiram com os cortes da grama.

O delineamento experimental utilizado foi um esquema fatorial $5 \times 4$, com 5 tratamentos de substrato e 4 níveis de sombreamento, e as médias foram submetidas ao teste de Tukey ao nível de 5\% de probabilidade e os resultados submetidos a transformação em $\mathrm{x}^{\wedge} 0,5$, seguida de análise de regressão, utilizando o programa SISVAR (FERREIRA, 2011).

\section{RESULTADOS E DISCUSSÃO}

Os dados da primeira análise de variância da altura, massa fresca e seca média da parte aérea da grama bermuda ( $C$. dactylon x $C$. transvaalensis), em cada um dos tratamentos são apresentados na Tabela 1. Analisando a altura média é possível observar que houve diferença significativa entre os níveis de sombreamento, entre os tratamentos de substratos e na interação dos fatores não houve diferença significativa ao nível de $5 \%$ de probabilidade. Já para a massa fresca e seca houve diferença significativa apenas para a interação substratos e níveis de sombreamento.

Tabela 1. Análise de variância de altura média, massa fresca e massa seca da grama bermuda na primeira avaliação. Ilha Solteira, 2016.

\begin{tabular}{lccl}
\hline \multicolumn{1}{c}{ FV } & Alt & MF & MS \\
\hline Sombreamento (A) & $8,72 *$ & $22,86 \mathrm{~ns}$ & $2,27 \mathrm{~ns}$ \\
Substrato (B) & $0,72 \mathrm{~ns}$ & $2,76 \mathrm{~ns}$ & $7,76 \mathrm{~ns}$ \\
Int. A x B & $0,32 \mathrm{~ns}$ & $16,83 *$ & $7,67 *$ \\
\hline CV \% & 35,68 & 18,85 & 27,12 \\
\hline
\end{tabular}

Alt. = altura média; $\mathrm{MF}$ = massa fresca média; MS = massa seca média.

A curva de regressão da primeira análise de altura da grama bermuda, nele é possível verificar o comportamento quadrático com tendência ao maior estiolamento nos tratamentos conforme havia o aumento na intensidade de sombreamento. Ao derivar a equação de regressão foi observado que o ponto máximo de sombreamento é 83,75\% (Figura 1).

Este resultado difere do apresentado por Schreiner (1987), que estudando o efeito do sombreamento em 4 gramíneas diferentes (Brachiaria decumbens, Digitaria decumbens, Hemarthria altissima, Paspalum notatum) obteve menores alturas quando submetia ao sombreamento mais intenso; já Maciel et al. (2011), estudando a influência do sombreamento no crescimento de grama bermuda ( $C$. dactylon), apresentaram resultados semelhantes aos encontrados no presente trabalho, onde a grama apresentou maiores alturas quando submetida ao sombreamento.

Isso comprova a diferença em relação tolerância ao sombreamento entre as diferentes espécies de gramíneas, como comentado por Coan (2005) e Gurgel (2003), que demonstraram que as diferentes espécies de grama apresentam variação na necessidade de luminosidade, sendo que normalmente as espécies de grama de clima quente, tais como 
esmeralda e bermuda, necessitam de plena insolação para atingir o ponto máximo de saturação de luz, sendo menos tolerantes ao sombreamento. A baixa incidência de luz é um fator altamente limitante para gramas bermuda, porém cada variedade tem mostrado diferentes níveis de tolerância, sendo capazes de manter um crescimento e qualidade aceitáveis mesmo com a radiação incidente abaixo da ideal.

A exposição a uma menor intensidade luminosa exige da planta uma maior eficiência da estrutura responsável pela realização da fotossíntese na captação e utilização da energia radiante, estimulando um maior desenvolvimento da planta, de forma que esta encontre meios de deixar a condição de baixa luminosidade (MARTINS et al., 2009), assim como foi possível observar no presente trabalho, com estiolamento da parte aérea da grama quando a mesma foi submetida ao maior nível de sombreamento.

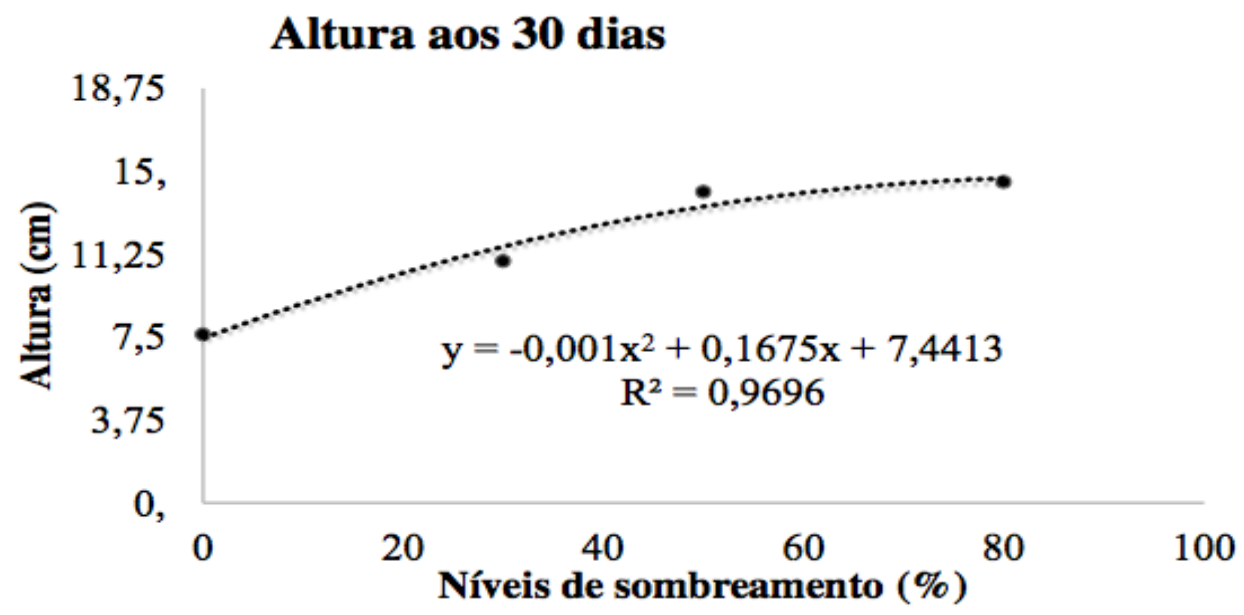

Figura 1. Análise de regressão dos dados da altura média na primeira avaliação. Ilha Solteira, 2016.

Na Figura 2, com a curva de regressão dos dados da primeira avaliação da massa fresca, pode-se observar o comportamento linear nas curvas dos substratos S1, S2 e S5, e quadrático das curvas dos demais substratos, derivando as equações foi possível determinar que o ponto máximo de acúmulo de massa fresca no substrato $\mathrm{S} 3$ foi verificado no sombreamento de $37,21 \%$; e o ponto mínimo foi observado no sombreamento de 38,30\%, para o substrato $\mathrm{S} 4$, tendo este substrato comportamento diferente do apresentado por S3. Tanto S1 quanto S2 apresentaram tendência ao aumento no acúmulo de massa fresca conforme se aumentava o nível de sombreamento, o substrato S5 apresentou comportamento inverso.

Oliveira et al. (2013), avaliando o comportamento de Andropogon gayanus e Panicum maximum sob sombreamento, verificaram que a $50 \%$ de sombreamento o acúmulo de massa fresca foi menor do que no nível de $30 \%$ de sombreamento e comparando a presença ou ausência de sombreamento foi possível observar nestas espécies que o sombreamento favoreceu o acúmulo de massa fresca. Assim como verificado nos substratos S1, S2 e S3 do presente trabalho. 


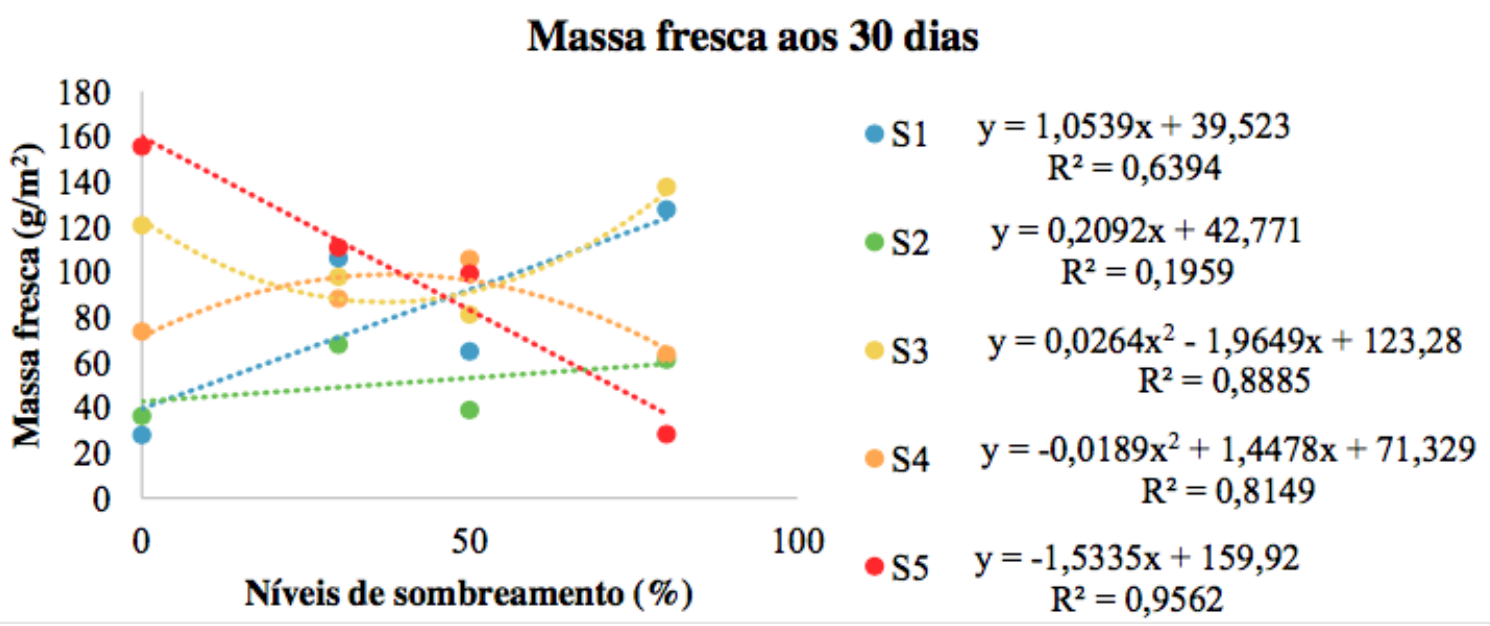

Figura 2. Análise de regressão dos dados da massa fresca média na primeira avaliação. Ilha Solteira, 2016.

As curvas de regressão dos dados de massa seca aos 30 dias mostra o comportamento linear dos substratos S1 e S5, porém com tendências opostas, enquanto o substrato $\mathrm{S} 1$ apresenta um aumento no acúmulo de massa seca, com o aumento do nível de sombreamento, o substrato S5 apresenta uma redução; os substratos S2, S3 e S4 apresentam comportamento quadrático da mesma, derivando-se as equações das curvas observa-se que o ponto máximo de sombreamento para ganho de massa seca variou entre 28,66 e 42,72\%, respectivamente os substratos $\mathrm{S} 4$ e $\mathrm{S} 2$, já o ponto mínimo de sombreamento foi observado no substrato S3, com valor de 43,36\% (Figura 3 ).

O resultado divergente também ao encontrado por Durr e Rangel (2000), que estudando a influência do sombreamento e solos no desenvolvimento de Panicum maximum, verificaram um maior acúmulo de massa seca no sombreamento mais intenso com solo contendo maior quantidade de matéria orgânica.

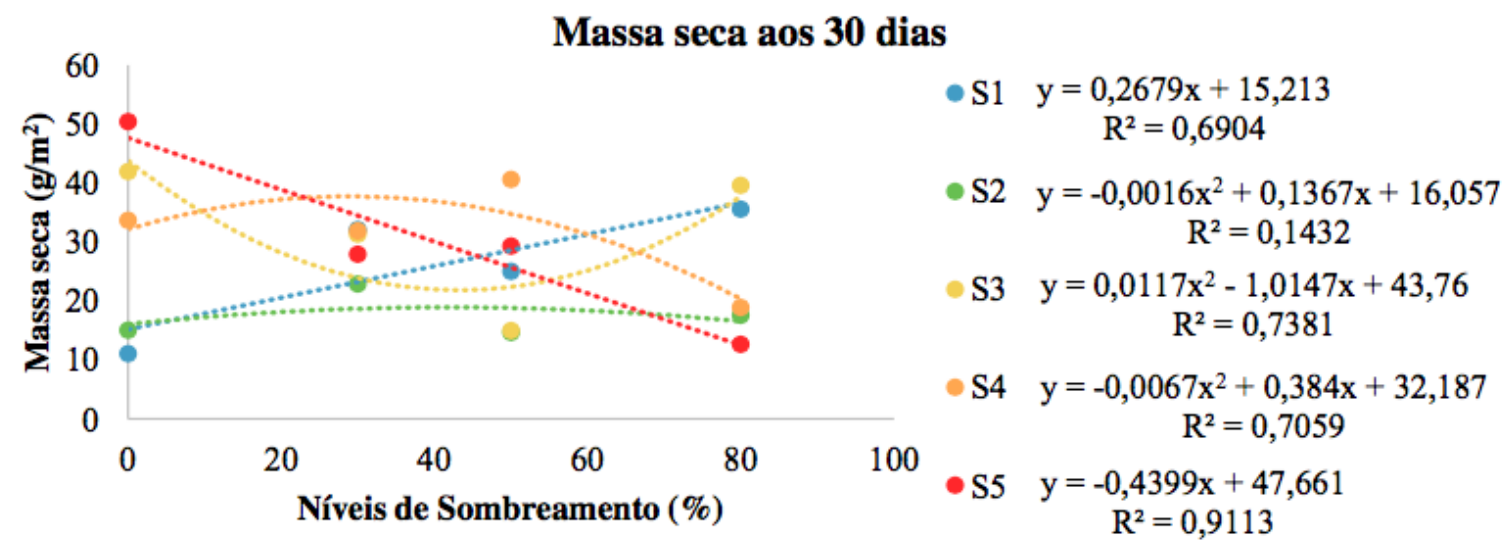

Figura 3. Análise de regressão dos dados da massa seca média na primeira avaliação. Ilha Solteira, 2016.

Assim como ocorreu na primeira análise, a variável altura também apresentou diferença significativa apenas para o fator sombreamento. $\mathrm{Na}$ segunda análise de massa fresca e massa seca houve diferença significativa ao nível de 5\% para ambos os fatores 
(sombreamento e substratos), assim como para a interação dos mesmos.

Tabela 2. Análise de variância de altura média, massa fresca e massa seca da grama bermuda na segunda avaliação. Ilha Solteira, 2016.

\begin{tabular}{lccc}
\hline \multicolumn{1}{c}{ FV } & Alt & MF & MS \\
\hline Sombreamento (A) & $11,71 *$ & $137,29 *$ & $82,79 *$ \\
Substrato (B) & $0,03 \mathrm{~ns}$ & $24,90 *$ & $14,26 *$ \\
Int. A x B & $0,31 \mathrm{~ns}$ & $31,58 *$ & $16,64 *$ \\
\hline CV \% & 33,34 & 23,84 & 31,73 \\
\hline
\end{tabular}

Alt. = altura média; MF = massa fresca média; MS = massa seca média.

A curva de regressão da primeira análise de altura da grama bermuda, nele é possível verificar o comportamento quadrático com tendência ao maior estiolamento nos tratamentos conforme havia o aumento na intensidade de sombreamento. Ao derivar a equação de regressão foi observado que o ponto máximo de sombreamento é 83,75\%. Na segunda avaliação, verifica-se o comportamento quadrático da curva de regressão com tendência de aumento na altura da grama resultante do aumento na intensidade de sombreamento, derivando-se a equação de regressão foi obtido o ponto mínimo de sombreamento é de $12,31 \%$.

Matta et al. (2009), avaliando o efeito do sombreamento em Panicum maximum cv. Mombaça, mostraram que os maiores comprimentos da parte aérea foram apresentadas pelas parcelas submetidas ao sombreamento mais elevado, da mesma forma que o presente trabalho.

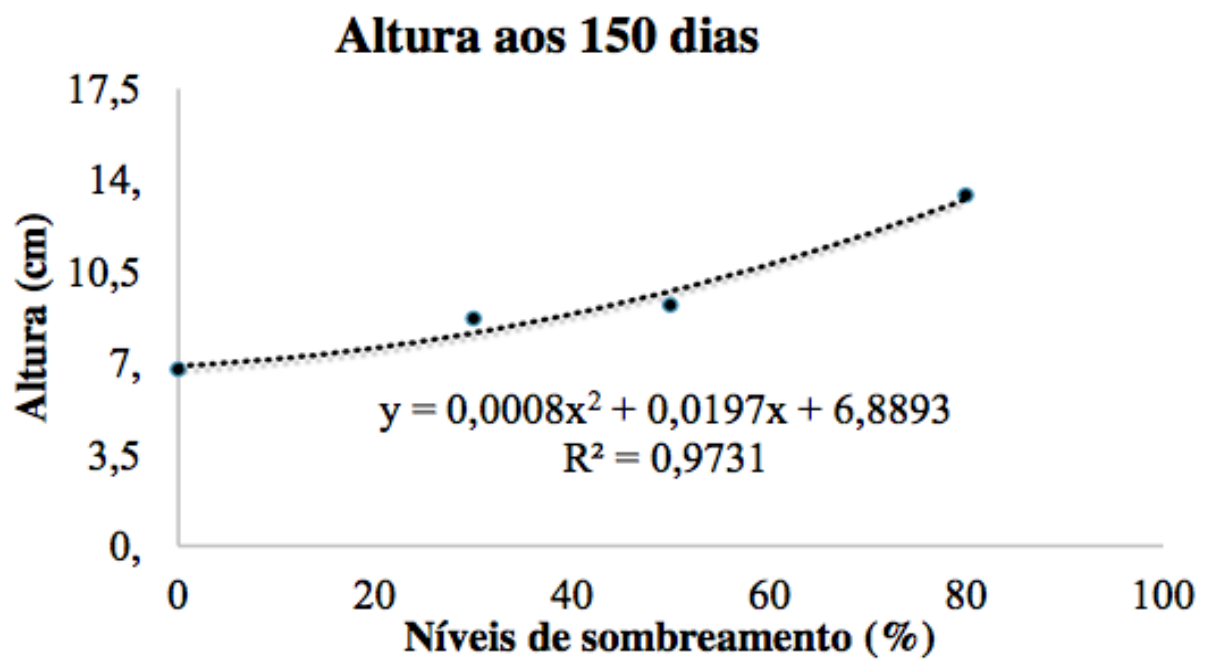

Figura 4. Análise de regressão dos dados da altura média na segunda avaliação. Ilha Solteira, 2016.

Na Figura 5, a curva de regressão dos dados da segunda avaliação, todos os substratos apresentaram comportamento quadrático. Derivando-se as equações, é possível verificar que o nível de sombreamento que apresenta o menor valor é de $41,05 \%$ para o substrato S1, o

Cultura Agronômica, Ilha Solteira, v.25, n.3, p.291-302, 2016 
ponto máximo de sombreamento variou entre $11,03 \%$ (S3) e 42,84\% (S2), tendo como média $23,77 \%$.

Ferreira et al. (2010), avaliando o desenvolvimento do capim tanzânia em condições de sombreamento, e verificaram o maior acúmulo de massa fresca da gramínea em condições de maior luminosidade, este resultado diverge do observado no presente trabalho.

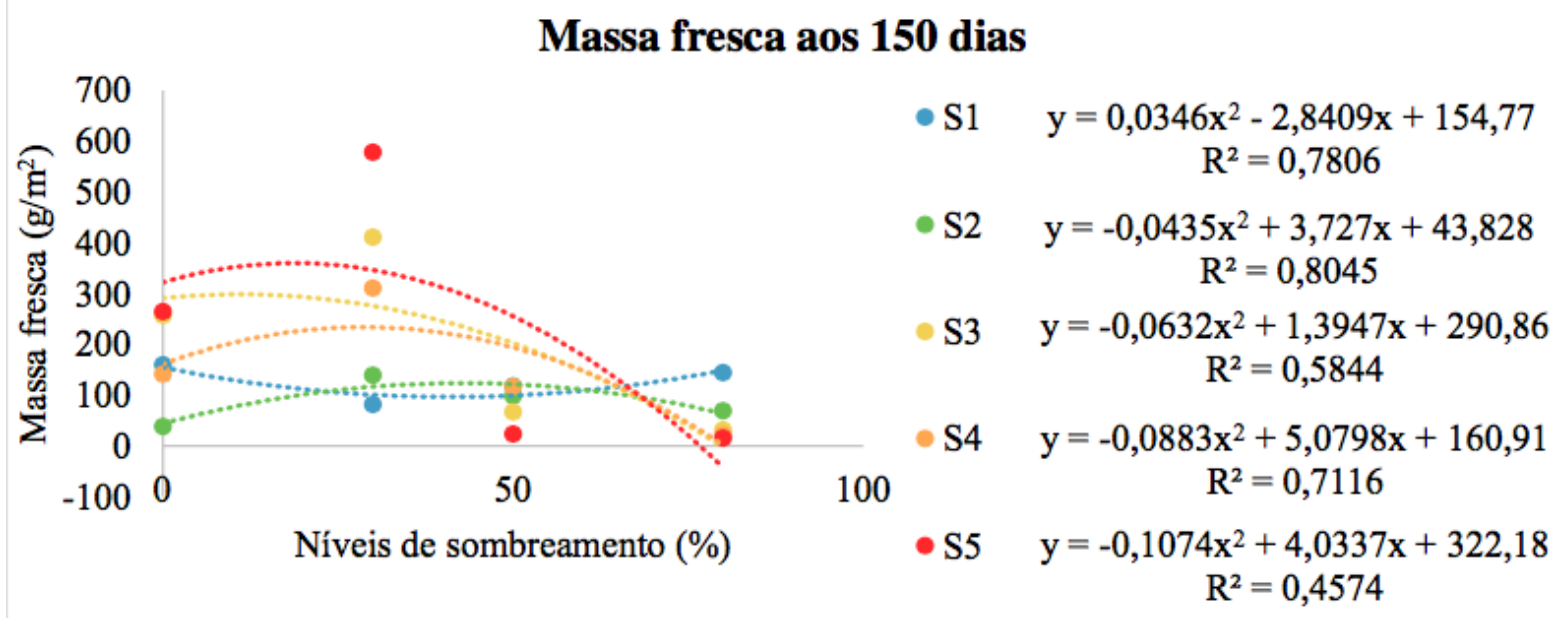

Figura 5. Análise de regressão dos dados de massa fresca na segunda avaliação. Ilha Solteira, 2016.

$\mathrm{Na}$ Figura 6, os substratos apresentaram comportamento quadrático, apresentando tendência de todos os substratos ao menor acúmulo de massa seca nos níveis mais intensos de sombreamento. O ponto máximo variou entre 6,74 e 40,46\% de sombreamento, respectivamente os substratos S3 e S2, tendo como valor médio 20,43\%, o substrato $\mathrm{S} 1$ teve o valor mínimo no sombreamento de $45,01 \%$.

Massa seca aos 150 dias

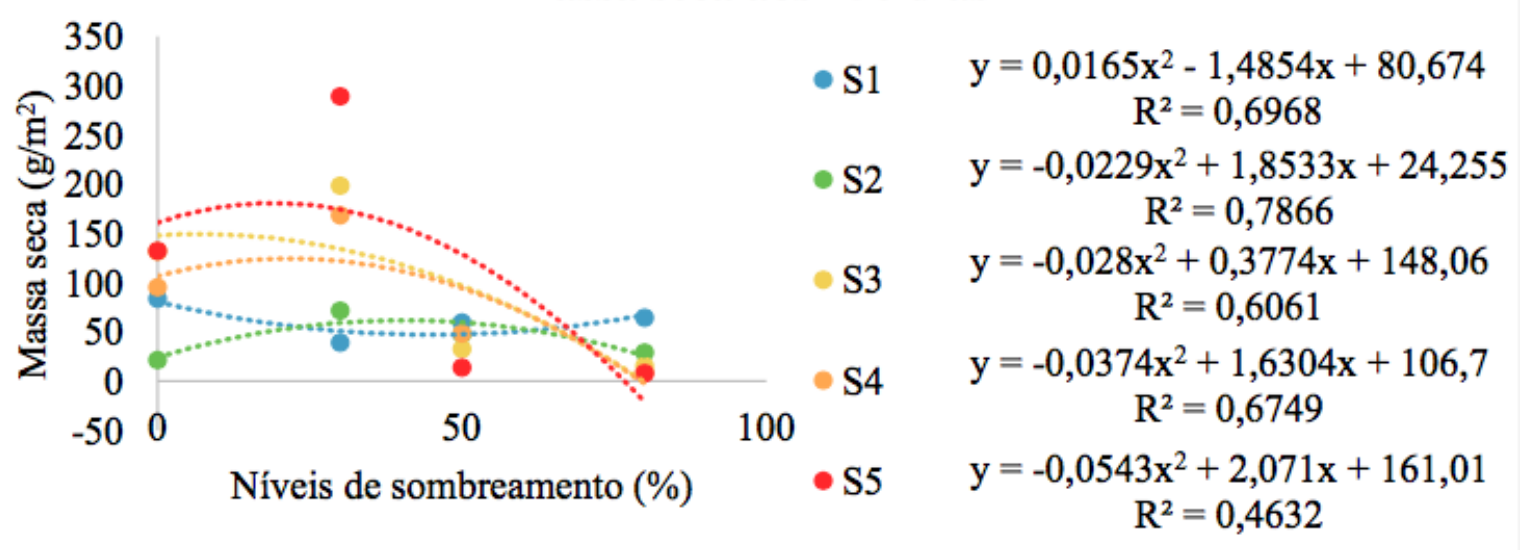

Figura 6. Análise de regressão dos dados de massa seca na segunda avaliação. Ilha Solteira, 2016.

O presente trabalho apresentou comportamento semelhante ao encontrado por Aldahir (2015), que avaliou o efeito do sombreamento no desenvolvimento de grama bermuda, onde houve redução no acúmulo de massa seca com o aumento na intensidade de sombreamento. Este resultado difere, porém, do encontrado por Matta et al. (2009), os quais avaliaram o 
efeito do sombreamento no desenvolvimento inicial de Panicum maximum cv. Mombaça e verificaram o menor ganho em massa seca da parcela submetida ao menor sombreamento.

\section{CONCLUSÃO}

Com base nos resultados apresentados no presente trabalho, os níveis mais intensos de sombreamento favoreceram o maior estiolamento da grama bermuda, porém há um menor acúmulo de matéria fresca e seca.

Em relação aos substratos, estes não apresentaram influência na altura da grama bermuda, porém afetou o ganho de massa fresca e seca, principalmente quando submetidos ao sombreamento.

Desta forma, pode-se concluir que há influência do sombreamento no desenvolvimento da grama bermuda, no entanto o tipo de substrato não influenciou no seu desenvolvimento. Assim sendo, é possível aferir que níveis elevados de sombreamento afeta negativamente o desempenho da grama bermuda, sendo toleráveis níveis intermediários de sombreamento.

\section{AGRADECIMENTOS}

Agradeço à Itograss pela doação da grama utilizada no experimento e a CAPES pela concessão da bolsa de mestrado.

\section{REFERÊNCIAS BIBLIOGRÁFICAS}

ALDAHIR, P. C. F. Utilization of 'TifGrand' bermudagrass for sports turf: wear tolerance, shade response, and quality improvement. 2015. $143 \mathrm{f}$. Tese (Doutorado em Filosofia) - Graduate Faculty of Auburn University, Auburn, 2015.

ALMEIDA, L. P.; ALVARENGA, A. A.; CASTRO, E. M.; ZANELA, S. M.; VIEIRA, C. V. Crescimento inicial de plantas de Cryptocaria aschersoniana Mez., submetidas a níveis de radiação solar. Ciência Rural, Santa Maria, v. 34, n. 1, p.83 - 88, 2004.

BURTON, G. W., JACKSON, J. E., KNOX, F. E. The influence of light reduction upon the production, persistence and chemical composition of coastal bermudagrass, Cynodon dactylon. Agronomy Journal, Madison, v. 51, n. 9, p.537-542, 1959.

CARVALHO, M. M.; FREITAS, V. P.; XAVIER, D. F. Início de florescimento, produção e valor nutritivo de gramíneas forrageiras tropicais sob condições de sombreamento natural. Pesquisa Agropecuária Brasileira, Brasília, v. 37, n. 5, p.717 - 722, 2002.

COAN, R. M. Efeito do sombreamento no desenvolvimento de grama-santo-agostinho [Stenotaphrum scundatum (Walter) Kuntze] e grama-esmeralda (Zoysia japonica Steud.). 2005. 35 f. Dissertação (Mestrado em Agronomia) - Faculdade de Ciências Agrárias e Veterinárias, Universidade Estadual Paulista Júlio de Mesquita Filho, 
Jaboticabal, 2005.

COAN, R. M. Crescimento de grama-esmeralda em diferentes exposições e declividades. 2008. 96 f. Tese (Doutorado em Agronomia) - Faculdade de Ciências Agrárias e Veterinárias, Universidade Estadual Paulista Júlio de Mesquita Filho, Jaboticabal, 2008.

COMITÊ ORGANIZADOR BRASILEIRO - COPA 2014. Recomendação técnica para gramados em estádios e CTs. 2009. Disponível em: http://infograma.com.br/textos/RECOMENDACAO_TECNICA_PARA_GRAMADOS_E M_ESTADIOS_e_CTs_LOC_2014\%5B1\%5D.pdf. Acesso em :13 fev. 2013.

DONG, M.; KROON, H. Plasticity in morphology and biomass allocation in Cynodon dactylon, a grass species forming stolons and rhizomes. Oikos, Copenhagen, v. 70, n. 1, p.99-106, 1994.

DURR, P. A.; RANGEL, J. The response of Panicum maximum to a simulated sub canopy environment. Tropical Grasslands, Queensland, v. 34, n. 2, p.110-117, 2000.

EMPRESA BRASILEIRA DE PESQUISA AGROPECUÁRIA - EMBRAPA. Sistema brasileiro de classificação de solos. Rio de Janeiro: EMBRAPA, 1999. 412 p.

FERREIRA, D. F. Sisvar: a computer statistical analysis system. Ciência e Agrotecnologia, Lavras, v. 35, n. 6, p.1039-1042, 2011.

FERREIRA, D. J.; ZANINE, A. M.; SOUTO, S. M.; DIAS, P. F. Capim tanzânia (Panicum maximum) sob sombreamento e manejo de corte. Archivos de Zootecnia, Córdoba, v. 59, n. 225, p.81-91, 2010.

GODOY, L. J. G. Adubação nitrogenada para produção de tapetes da grama Sto. Agostinho e Esmeralda. 2005.106 f. Tese (Doutorado em Agronomia - Agricultura) Faculdade de Ciências Agronômicas, Universidade Estadual Paulista, Botucatu, 2005.

GODOY, L. J. G.; VILLAS BÔAS, R. L. Nutrição em gramados. In: SIGRA - SIMPÓSIO SOBRE GRAMADOS, 1., 2003, Botucatu. Anais... Botucatu: FCA/UNESP, 2003. p. 0148.

GURGEL, R. G. A. Principais espécies e variedades de grama. In: SIGRA - SIMPÓSIO SOBRE GRAMADOS, 1., 2003, Botucatu. Anais... Botucatu: FCA/UNESP, 2003. p. 0123.

HART, R.H., HUGHES, R.H., LEWIS, C. E., MONSON, W.G. Effect of nitrogen and shading on yield and quality of grass grown under young slash pines. Agronomy Journal, Madison, v. 62, n. 2, p.285-287, 1970.

HENDERSON, M. S., ROBINSON, D. L. Environmental influences on yield and in vitro true digestibility of warm-season perennial grasses and the relationships to fiber components. Agronomy Journal, Madison, v. 74, n. 7, p.943-946, 1982.

MACIEL, C. D. G.; POLETINE, J. P.; RAIMONDI, M. A.; RODRIGUES, M.; RIBEIRO, Cultura Agronômica, Ilha Solteira, v.25, n.3, p.291-302, 2016 
R. B.; COSTA, R. S.; MAIO, R. M. D. Desenvolvimento de gramados submetidos à aplicação de retardadores de crescimento em diferentes condições de luminosidade. Planta Daninha, Viçosa, v. 29, n. 2, p.383-395, 2011.

MARTINS, J. R.; ALVARENGA, A. A.; CASTRO, E. M.; SIlVA, A. P. O.; OLIVEIRA, C.; ALVES, E. Anatomia foliar de plantas de alfavaca-cravo cultivadas sob malhas coloridas. Ciência rural, Santa Maria, v. 39, n. 1, p.82-87, 2009.

MATTA, P. M.; SOUTO, S. M.; DIAS, P. F.; COLOMBARI, A. A.; AZEVEDO, B. C.; VIEIRA, M. S. Efeito de sombreamento no estabelecimento de Panicum maximum cv. Mombaça. Archivos Latinoamericanos de Produccion Animal, Mayaguez, v. 17, n. 3-4, p.97-102, 2009.

MORAES, M. H.; CORA, J. E.; ALMEIDA, A. B. Compactação em gramados: como avaliar e propostas para minimizar o problema. In: SIGRA - SIMPÓSIO SOBRE GRAMADOS, 4., 2008, Botucatu. Tópicos atuais em gramados, Botucatu: FCA/UNESP, 2008. p. 46 - 55, 2008.

MORITA, O., GOTO, M., EHARA, H. Growth and dry matter production of pasture plants grown under reduced light conditions of summer season. Bulletin of the Faculty of Bioresources, Mie, v. 12, n. 1, p.11-20, 1994.

OLIVEIRA, C. A. V. M.; PIVETTA, K. F. L.; BARTOLOMEU, E. A.; RODRIGUES, M. A.; CIPOLINI, N.; COAN, R. M. Avaliação do vigor de sementes de Cynodon dactylon pelo teste de envelhecimento acelerado. In: SIGRA - SIMPÓSIO SOBRE GRAMADOS, 4., 2008, Botucatu. Tópicos atuais em gramados, Botucatu: FCA/UNESP, 2008. p. 128 - 132, 2008.

OLIVEIRA, F. L. R.; MOTA, V. A.; RAMOS, M. S.; SANTOS, L. D. T.; OLIVEIRA, N. J. F.; GERASEEV, L. C. Comportamento de Andropogon gayanus cv. 'planaltina' e Panicum maximum cv. 'tanzânia' sob sombreamento. Ciência Rural, Santa Maria, v. 43, n. 2, p.348-354, 2013.

SCHMIDT, R. E., BLASER, R. E. Effect of temperature, light and nitrogen on growth and metabolism of "tifgreen" bermuda grass (Cynodon spp). Crop Science, Madison, v. 9, n. 1, p.5-9, 1969.

SCHREINER, H. G. Tolerância de quatro gramínea forrageiras a diferentes graus de sombreamento. Boletim de Pesquisa Florestal, Colombo, n. 15, p. 61-72, 1987.

UNIVERSIDADE ESTADUAL PAULISTA - UNESP. Dados climáticos de Ilha Solteira. Ilha Solteira: Departamento de Fitossanidade, Engenharia Rural e Solos / Área de Hidráulica e Irrigação, 2014. Disponível em: http://clima.feis.unesp.br/dados_diarios.php . Acesso em: 29 nov. 2014.

WHATley, J. M.; WHATley, F. R. A luz e a vida das plantas. v. 30. São Paulo: Editora da Universidade de São Paulo, 1982. 100 p.

Cultura Agronômica, Ilha Solteira, v.25, n.3, p.291-302, 2016 
